\title{
Produção de beterraba em função do espaçamento
}

\author{
Carla V Corrêa; Antonio II Cardoso; Luis G Souza; Walter LP Antunes; Luis A Magolbo
}

${ }^{1}$ UNESP-FCA Depto Horticultura, C. Postal 237, 18603-970 Botucatu-SP; cvcorrea@fca.unesp.br; ismaeldh@fca.unesp.br; lgdsouza@ fca.unesp.br; wldpantunes@fca.unesp.br; luis_magolbo@hotmail.com

\section{RESUMO}

Atualmente alguns híbridos importados têm substituído as tradicionais cultivares de beterraba de mesa, sem no entanto, desenvolver estudos básicos sobre a melhor densidade de plantio para as condições brasileiras. O objetivo deste trabalho foi avaliar o efeito do espaçamento entre linhas e entre plantas na produção de beterraba híbrido Boro. O experimento foi conduzido em campo da UNESP em Botucatu-SP, de 10 de setembro a 8 de dezembro de 2010. Foram estudados dois fatores, espaçamentos entre linhas (EL) de 20 e 25 $\mathrm{cm}$, e 7,$5 ; 10,0$ e $12,5 \mathrm{~cm}$ entre plantas (EP), no esquema fatorial 2 EL x $3 \mathrm{EP}$, totalizando seis tratamentos (populações variando de 246.400 a 513.333 plantas ha $^{-1}$, considerando-se canteiros com 1,0 $\mathrm{m}$ de largura e espaço entre canteiros de $0,3 \mathrm{~m}$ ). O delineamento experimental foi em blocos ao acaso, com cinco repetições e parcelas de $2 \mathrm{~m}^{2}$. As mudas foram produzidas em bandejas de polipropileno com 288 células. A irrigação foi por aspersão e a adubação foi igual para todos os tratamentos, seguindo a recomendação para o estado de São Paulo. A maior massa fresca por raiz $(116,1 \mathrm{~g})$ foi obtida no EL de 25,0 cm. Em relação ao comprimento da raiz, observaram-se diferenças significativas apenas para o EP, sendo que o maior espaçamento, $12,5 \mathrm{~cm}$, resultou em maior comprimento $(63,1 \mathrm{~mm})$. Foram obtidos maiores valores de diâmetro das raízes quanto maiores os EP $(65,6 \mathrm{~mm}$ para $12,5 \mathrm{~cm})$ e EL $(63,1 \mathrm{~mm}$ para $25 \mathrm{~cm})$. A maior produtividade $\left(44,7 \mathrm{tha}^{-1}\right)$ foi obtida no menor $\operatorname{EP}(7,5 \mathrm{~cm})$, enquanto que o EL não afetou a produtividade. Pode-se concluir que o melhor EP foi de 7,5 cm pela maior produtividade. Quanto ao tamanho da raiz, tanto o maior EL $(25 \mathrm{~cm})$ como o maior EP $(12,5 \mathrm{~cm})$ resultaram em raízes com maiores massa média e diâmetro.

Palavras chave: Beta vulgaris, densidade de plantas, população de plantas.

\begin{abstract}
Yield of beet depending on spacing

Nowadays, some imported hybrids have replaced the traditional beet cultivars. However, no basic studies about the best plant density are available for the Brazilian environmental conditions. The objective of this study was to evaluate the effect of spacing between lines and between plants on hybrid beet production. Experiment was set up in field at UNESP, from September $10^{\text {th }}$ to December $8^{\text {th }}, 2010$. Two factors were studied, spacing between lines (EL) of 20 and 25 $\mathrm{cm}$, and between plants (EP) of 7.5; 10.0 and $12.5 \mathrm{~cm}$, in factorial scheme $2 \mathrm{EL}$ × $3 \mathrm{EP}$, totalizing six treatments (plant populations from 246,400 to 513,333 plants ha $^{-1}$, considering beds with $1.0 \mathrm{~m}$ wide and spacing between beds of $0.3 \mathrm{~m}$ ). Experimental design was randomized blocks, with five replications and plots of $2 \mathrm{~m}^{2}$. Seeds of Boro hybrid were sown in polypropylene trays with 288 cells. The highest root average weight (116.1 g) was obtained in EL of 25.0 $\mathrm{cm}$. For root length, difference was observed only for EP, with higher length $(63.1 \mathrm{~mm})$ with the highest spacing $(12.5 \mathrm{~cm})$. The higher EP or EL, the higher the values for root diameters were observed (65.6 $\mathrm{mm}$ for EP of $12.5 \mathrm{~cm}$ and $63.1 \mathrm{~mm}$ for EL of $25 \mathrm{~cm})$. The highest yield $\left(44.7 \mathrm{t} \mathrm{ha}^{-1}\right)$ was obtained for the least EP $(7.5 \mathrm{~cm})$, while EL did not affect yield. Concluding, the best EP is $7.5 \mathrm{~cm}$, because of the highest yield. For root dimensions, the highest EL $(25.0 \mathrm{~cm})$ and EP $(12.5 \mathrm{~cm})$ resulted in heavier roots with higher diameter.
\end{abstract}

Keywords: Beta vulgaris, density, plant population.

\section{(Recebido para publicação em 18 de agosto de 2012; aceito em 22 de novembro de 2013) (Received on August 18, 2012; accepted on November 22, 2013)}

\begin{abstract}
A beterraba (Beta vulgaris) é uma dicotiledônea pertencente à família Quenopodiaceae. Trata-se de uma planta bienal, tendo melhor produção de raízes em condições de outono/inverno (Fontes, 2005). Segundo Filgueira (2008), são três os tipos de beterraba existentes: beterraba hortícola, ou de mesa, beterraba açucareira e beterraba forrageira, sendo que no Brasil somente a beterraba hortícola é cultivada comercialmente.
\end{abstract}

Apesar de não estar entre as hortaliças de maior valor econômico, é importante em um grande número de pequenas propriedades dos cinturões verdes que apresentam grande diversidade de cultivo de hortaliças. Entretanto, nos últimos anos, houve expansão para novas fronteiras agrícolas mais distantes dos centros consumidores, por permitir transporte a longas distâncias. São exemplos desta expansão o triângulo mineiro e São Gotardo-MG e Irecê-BA, onde o custo de produção é menor e o clima mais estável (Cardoso, 2008).

A cultivar Early Wonder ainda é a mais conhecida beterraba hortícola. Porém, nos últimos anos no Brasil, tem-se aumentado a área, com híbridos importados (Cardoso, 2008) e são poucas as pesquisas com estes novos materiais, o que pode estar limitando o potencial produtivo dos mesmos.

Buscando a otimização da produção, um dos primeiros pontos a se considerar é o espaçamento ideal, pois uma maneira óbvia de se tentar aumentar a produtividade de uma cultura é plantar-se um maior número de plantas por unidade de área. Entretanto, na maioria das culturas, o aumento de produtividade por esse método tem um limite, considerando 
que com o aumento da densidade há um aumento na competição entre plantas, e o desenvolvimento individual de cada planta é prejudicado, podendo, inclusive, ocorrer queda no rendimento e/ ou na qualidade (Minami et al., 1998). No caso da beterraba, um atributo de qualidade é o diâmetro da raiz tuberosa que pode ser reduzido em condições de maior população de plantas.

Em maiores densidades de plantio há aumento na competição por área e nutrientes, reduzindo a fotossíntese e a concentração de nutrientes, diminuindo o crescimento das plantas, além de interferir diretamente na produção e qualidade. Por meio do adensamento também busca-se potencializar a capacidade de supressão da cultura sobre a comunidade infestante, promovendo sombreamento precoce do solo, afetando, assim, negativamente o crescimento e desenvolvimento das plantas daninhas (Carvalho \& Guzzo, 2008). Estes autores relataram aumento de $17 \%$ na produtividade da beterraba ao se passar de 40 (espaçamento de $25 \times 10 \mathrm{~cm}$ ) para $50(20$ x $10 \mathrm{~cm})$ plantas $\mathrm{m}^{-2}$. Já Zárate et al. (2008) não obtiveram diferença na produtividade com a beterraba 'Tall Top Early Wonder' ao estudarem populações de plantas (264.000 a 660.000 plantas ha-1).

Segundo Filgueira (2008), o espaçamento para a cultura é de 25 a $30 \mathrm{~cm}$ entre linhas e 8 a $10 \mathrm{~cm}$ entre plantas. O espaçamento citado por Trani et al. (1997) é de 25 a 30 x 10 a $15 \mathrm{~cm}$. Cardoso (2008) cita que a população normalmente utilizada é de 300 a 350 mil plantas por hectare, porém há a tendência de alguns produtores utilizarem populações maiores visando incrementar a produção por área plantada.

O objetivo deste trabalho foi avaliar o efeito do espaçamento entre linhas e entre plantas na produção de beterraba com produção de mudas em bandejas de polipropileno.

\section{MATERIAL E MÉTODOS}

O experimento foi conduzido na $\mathrm{Fa}$ zenda Experimental São Manuel, localizada no município de São Manuel-SP, pertencente à UNESP em Botucatu-SP
(22 $46^{\prime}$ 's; 48 34'O; $740 \mathrm{~m}$ de altitude). O clima predominante, segundo a classificação de Köppen, é tipo Cfa, temperado quente (mesotérmico) úmido e a temperatura média do mês mais quente é superior a $22^{\circ} \mathrm{C}$, com precipitação média anual de 1377 mm (Cunha \& Martins, 2009).

O solo da área de cultivo é considerado Latossolo Vermelho Distrófico Típico. Os resultados obtidos na análise química, segundo metodologia de Raij et al. (2001), na camada de $0-20 \mathrm{~cm}$ de profundidade, antes da instalação do experimento foram: $\mathrm{pH}=5,6 ; \mathrm{M} . \mathrm{O}=19$ $\mathrm{g} \mathrm{dm}^{-3} ; \mathrm{P}_{\text {resina }}=98 \mathrm{mg} \mathrm{dm}^{-3} ; \mathrm{H}+\mathrm{Al}=12$ $\mathrm{mmol}_{\mathrm{c}} \mathrm{dm}^{-3} ; \mathrm{K}=1,9 \mathrm{mmol}_{\mathrm{c}} \mathrm{dm}^{-3} ; \mathrm{Ca}=$ $37 \mathrm{mmol}_{\mathrm{c}} \mathrm{dm}^{-3} ; \mathrm{Mg}=13 \mathrm{mmol}_{\mathrm{c}} \mathrm{dm}^{-3}$; $\mathrm{SB}=52 \mathrm{mmol}_{\mathrm{c}} \mathrm{dm}^{-3} ; \mathrm{CTC}=64 \mathrm{mmol}_{\mathrm{c}}$ $\mathrm{dm}^{-3}$ e $\mathrm{V}=81 \%$. A adubação foi baseada na recomendação de Trani et al. (1997) para o estado de São Paulo, aplicando-se 20,180 e $120 \mathrm{~kg} \mathrm{ha}^{-1}$ de $\mathrm{N}, \mathrm{P}_{2} \mathrm{O}_{5}$ e $\mathrm{K}_{2} \mathrm{O}$, respectivamente. $\mathrm{O}$ híbrido utilizado foi Boro (Bejo ${ }^{\circledR}$ ) e a semeadura, realizada em 10 de setembro de 2010, em bandejas de polipropileno com 288 células contendo substrato comercial para hortaliças, colocando-se uma semente por célula. O transplante foi realizado em 10 de outubro de 2010 em canteiros de 1,0 $\mathrm{m}$ de largura, 50,0 $\mathrm{m}$ de comprimento e 0,2 $\mathrm{m}$ de altura, espaçados em 0,3 m.

Foram estudados dois fatores, espaçamentos entre linhas (EL) de 20 e 25 $\mathrm{cm}$ e entre plantas (EP) de 7,5; 10,0 e $12,5 \mathrm{~cm}$, no esquema fatorial $2 \mathrm{EL} \times 3$ EP, totalizando 6 tratamentos $(246.400$ a 513.333 plantas ha-1, considerando-se canteiros com 1,0 m e espaço entre canteiros de $0,3 \mathrm{~m}$ ). As parcelas foram de 2,0 $\mathrm{m}^{2}$, sendo avaliadas as plantas das duas linhas centrais das parcelas. $\mathrm{O}$ delineamento experimental utilizado foi de blocos ao acaso, com cinco repetições.

Os tratos culturais compreenderam o desbaste na bandeja, capinas, realizadas a cada 14 dias e irrigação por micro-aspersão, a cada dois dias, no local definitivo. A adubação de cobertura foi feita de acordo com as recomendações de Trani et al. (1997), fornecendo 45 $\mathrm{kg} \mathrm{ha}^{-1}$ de $\mathrm{K}_{2} \mathrm{O}$, na forma de cloreto de potássio, e $90 \mathrm{~kg} \mathrm{ha}^{-1}$ de $\mathrm{N}$, na forma de uréia, parcelados aos 15, 30 e 45 dias após o transplante, aplicando-se 1/3 da dose recomendada em cada data.
Não foi necessário o uso de controle fitossanitário.

A colheita foi realizada em 08 de dezembro de 2010. Foram avaliados a massa fresca de raízes e de folhas por parcela, número de folhas, altura das plantas, diâmetro e comprimento das raízes. Para obtenção da massa foi utilizada balança semi-analítica, expressando os valores em gramas, e para diâmetro e comprimento foi utilizado paquímetro digital, com os resultados expressos em milímetros. A partir destes, obtiveram-se a massa média de raiz e de folha por planta e a produtividade ( $\left.\mathrm{t} \mathrm{ha}^{-1}\right)$, sendo esta última o produto da massa média pelo número de plantas por ha.

A análise estatística foi feita no esquema fatorial $2 \times 3$ (EL x EP) e a comparação das médias foi feita pelo teste de Tukey, a 5\% de probabilidade.

\section{RESULTADOS E DISCUSSÃO}

A interação espaçamento entre linhas (EL) por entre plantas (EP) não foi significativa, permitindo a discussão dos fatores EL e EP isoladamente.

Obteve-se a maior produtividade (44,7 t ha-1) no menor EP, porém, o EL não afetou a produtividade (Tabelas 1 e 2). Esta maior produtividade no menor EP, provavelmente, seja resultado da maior população, com média de 462.000, 346.500 e 277.200 plantas ha ${ }^{-1}$ nos EP de 7,5, 10,0 e 12,5 cm, respectivamente. Já para os EL as diferenças na população não foram tão acentuadas, com 402.111 e 321.689 plantas ha $^{-1}$ nos EL de 20 e $25 \mathrm{~cm}$, com produtividades de 35,4 e 37,2 $\mathrm{t} \mathrm{ha}^{-1}$, respectivamente. Este resultado mostra que o híbrido utilizado, nas condições desta pesquisa, pode tolerar adensamento com ganho de produtividade. Também Carvalho \& Guzzo (2008) obtiveram acréscimo de produtividade em beterraba com aumento da densidade. Já Zárate et al. (2008) não obtiveram diferença na produtividade com a beterraba 'Tall Top Early Wonder' ao estudarem populações de plantas que variaram de 264.000 a 660.000 plantas ha $^{-1}$.

Quanto aos valores de produtividade obtidos, foram superiores aos encontrados por Guimarães et al. (2002), Tolentino Júnior et al. (2002), Trani et 
Tabela 1. Produtividade de raízes (Prod), massa média (MR), diâmetro (DR) e comprimento (CR) de raiz e massa de folhas (MF) por planta de beterraba em função do espaçamento entre plantas (EP) [root yield (Prod), average weight (MR), diameter (DR) and length (CR) of root and shoot weight (MF) per plant of beet depending on spacing among plants (EP)]. São Manuel, UNESP, 2010.

\begin{tabular}{lccccc}
\hline $\begin{array}{l}\text { EP } \\
(\mathbf{c m})\end{array}$ & $\begin{array}{c}\text { Prod } \\
\left.\mathbf{( t ~ h a}^{-1}\right)\end{array}$ & $\begin{array}{c}\text { MR } \\
\left(\mathbf{g ~ r a i z}^{-1}\right)\end{array}$ & $\begin{array}{c}\text { DR } \\
(\mathbf{m m})\end{array}$ & $\begin{array}{c}\text { CR } \\
(\mathbf{m m})\end{array}$ & $\begin{array}{c}\text { MF } \\
\left(\mathbf{g ~ p l a n t a}^{-1}\right)\end{array}$ \\
\hline 7,5 & $44,7 \mathrm{a}$ & $98,8 \mathrm{~b}$ & $58,6 \mathrm{~b}$ & $56,1 \mathrm{~b}$ & $167,3 \mathrm{a}$ \\
10,0 & $35,0 \mathrm{~b}$ & $101,3 \mathrm{ab}$ & $58,8 \mathrm{~b}$ & $58,3 \mathrm{ab}$ & $152,0 \mathrm{ab}$ \\
12,5 & $29,2 \mathrm{~b}$ & $107,6 \mathrm{a}$ & $65,6 \mathrm{a}$ & $63,1 \mathrm{a}$ & $135,9 \mathrm{~b}$ \\
\hline $\mathrm{CV}(\%)$ & 15,9 & 15,6 & 8,2 & 8,0 & 16,5 \\
\hline
\end{tabular}

Médias, nas colunas, seguidas de mesma letra não diferem pelo teste de Tukey, $p<0,05$ (means in columns, followed by same letter do not differ by Tukey test, $\mathrm{p}<0.05$ ).

Tabela 2. Produtividade de raízes (Prod), massa média (MR), diâmetro (DR) e comprimento (CR) de raiz e massa de folhas (MF) por planta de beterraba em função do espaçamento entre linhas (EL) [root yield (Prod), average weight (MR), diameter (DR) and length (CR) of root and shoot weight (MF) per plant of beet depending on spacing between lines (EL)]. São Manuel, UNESP, 2010.

\begin{tabular}{lccccc}
\hline EL $\mathbf{( c m )}$ & $\begin{array}{c}\text { Prod } \\
\left.\mathbf{( t ~ h a ~}^{-1}\right)\end{array}$ & $\begin{array}{c}\text { MR } \\
\left(\mathbf{g ~ r a i z}^{-1}\right)\end{array}$ & $\begin{array}{c}\text { DR } \\
(\mathbf{m m})\end{array}$ & $\begin{array}{c}\mathbf{C R} \\
(\mathbf{m m})\end{array}$ & $\begin{array}{c}\text { MF } \\
\left(\mathbf{g ~ p l a n t a}^{-1}\right)\end{array}$ \\
\hline 20 & $35,4 \mathrm{a}$ & $89,0 \mathrm{~b}$ & $58,9 \mathrm{~b}$ & $59,2 \mathrm{a}$ & $176,3 \mathrm{a}$ \\
25 & $37,2 \mathrm{a}$ & $116,1 \mathrm{a}$ & $63,1 \mathrm{a}$ & $59,1 \mathrm{a}$ & $127,2 \mathrm{~b}$ \\
\hline $\mathrm{CV}(\%)$ & 15,9 & 15,6 & 8,2 & 8,0 & 16,5 \\
\hline
\end{tabular}

Médias, nas colunas, seguidas de mesma letra não diferem pelo teste de Tukey, $\mathrm{p}<0,05$ (means in columns, followed by same letter do not differ by Tukey test, $\mathrm{p}<0.05$ ).

al. (2005), Carvalho \& Guzzo (2008), Costa et al. (2008) e Zárate et al. (2010), que obtiveram produtividades máximas variando de 15 a $40 \mathrm{t} \mathrm{ha}^{-1}$. No entanto, estes autores utilizaram uma cultivar de polinização aberta, geralmente a Early Wonder, e, segundo Maluf(2001), os híbridos, quando bem adaptados, apresentam maior potencial produtivo que as cultivares de polinização aberta. Além disto, a maioria destes autores utilizou populações de plantas inferiores aos desta pesquisa. Filgueira (2008) cita produtividades no Brasil de 20 a $35 \mathrm{t} \mathrm{ha}^{-1}$, porém com população de até 350.000 plantas $a^{-1}$. Além da população de plantas superior nesta pesquisa, as condições ambientais foram favoráveis, com ausência de doenças, tanto que não houve necessidade de pulverizações com fungicidas. Outro fator que pode afetar a produtividade é o ciclo da cultura. Quanto maior o ciclo, maior a massa média de raiz e a produtividade (Guimarães et al., 2002). Nesta pesquisa o ciclo total foi de 89 dias.

Apesar do aumento da produtividade com a redução do EP, quanto menores o
EP e EL, menor a massa média de raiz (Tabelas 1 e 2). A redução no tamanho das raízes associada ao aumento da densidade de plantio deve ter ocorrido devido à competição entre plantas por luz e nutrientes. Em maiores densidades há redução na disponibilidade de nutrientes para cada planta individualmente, podendo ser um fator para redução no crescimento. Na presente pesquisa, a adubação foi igual para todos os tratamentos, segundo a recomendação de Trani et al. (1997) para o estado de São Paulo, sendo esta recomendação para uma população de plantas (espaçamento de 0,25 a 0,30 $\mathrm{x} 0,10$ a $0,15 \mathrm{~m}$ ) inferior à maioria das avaliadas neste experimento. Portanto, talvez com doses superiores de fertilizantes fosse possível obter raízes maiores, por reduzir o efeito da competição por nutrientes. Em rúcula, Purquerio et al. (2007) observaram que o efeito da redução na produtividade com menor população de plantas era parcialmente compensada com aumentos nos níveis de adubação com nitrogênio, apesar do efeito da população de plantas ter sido mais pronunciado na produtividade que o efeito da adubação. Resultados semelhantes foram obtidos por Aquino et al. (2005) para a massa média por cabeça em repolho.

O EL não afetou o comprimento das raízes, enquanto que no maior $\mathrm{EP}, 12,5$ $\mathrm{cm}$, foram obtidas raízes mais compridas (63,1 mm) (Tabelas 1 e 2), mostrando que maior competição intraespecífica na linha pode ter reduzido o tamanho da raiz em beterraba. Os valores observados são superiores aos relatados por Zárate et al. (2008), máximo de 55 $\mathrm{mm}$. Com relação ao diâmetro de raiz, os maiores valores foram de $65,6 \mathrm{~mm}$ para o EP de 12,5 $\mathrm{cm}$ e de 63,1 $\mathrm{mm}$ para o EL de $25 \mathrm{~cm}$ (Tabelas 1 e 2). Esses valores estão próximos dos encontrados por Zárate et al. (2008), com máximo de $65,6 \mathrm{~mm}$ e pouco superiores aos obtidos por Costa et al. (2008), com diâmetros variando de 47,1 a 55,1 mm, ambos com a cultivar Early Wonder.

Apesar do aumento na produtividade no menor EP, houve pequena redução no diâmetro das raízes em relação ao maior EP. Porém, apesar de significativa, a diferença foi pequena $(7,0 \mathrm{~mm})$, não afetando a qualidade das raízes, pois os valores obtidos foram sempre iguais ou superiores aos relatados na literatura $\mathrm{e}$ todas as raízes com diâmetro superior a $40 \mathrm{~mm}$ que, segundo Horta et al. (2004), podem ser consideradas comerciais.

Não foram observadas diferenças para o número de folhas por planta (média de 12 folhas) e altura das plantas (média de $38 \mathrm{~cm}$ ) ao final do ciclo. Zárate et al. (2008) também não observaram diferença na altura das plantas (média de $24 \mathrm{~cm}$ ) em função das densidades de plantio (264.000 a 660.000 plantas ha $^{-1}$ ) com a cultivar Early Wonder. Em rabanete, Minami et al. (1998) também não obtiveram diferença para número de folhas em função dos EP e EL avaliados.

Quanto à massa de folhas, maiores valores foram obtidos nos menores $\mathrm{EP} \mathrm{e}$ EL (Tabelas 1 e 2). Este resultado difere do obtido por Zárate et al. (2008) que relataram que a população de plantas não afetou a massa de folhas por planta em beterraba.

Pode-se concluir que o melhor EP foi de $7,5 \mathrm{~cm}$ pela maior produtividade. Quanto ao tamanho da raiz, tanto o maior EL $(25 \mathrm{~cm})$ como o maior EP 
$(12,5 \mathrm{~cm})$ resultaram em raízes com maiores massa média e diâmetro.

\section{AGRADECIMENTOS}

Os autores agradecem à FAPESP e ao CNPq, pela concessão de bolsas.

\section{REFERÊNCIAS}

AQUINO LA; PUIATTI M; PEREIRA PRG; PEREIRA FHF; CASTRO MRS; LADEIRA IR. 2005. Características produtivas do repolho em função de espaçamentos e doses de nitrogênio. Horticultura Brasileira 23: 266-270.

CARDOSO AII. 2008. Produção de beterraba híbrida no Brasil. Revista Campo \& Negócios 40: 26-27.

CARVALHO LB; GUZZO CD. 2008. Adensamento da beterraba no manejo de plantas daninhas. Planta Daninha 26: 73-82.

COSTA RNT; VASCONCELOS JP; SILVA LA; NESS RLL. 2008. Interferência do excesso de água no solo e componentes de produção em beterraba. Horticultura Brasileira 26: 74-77.

CUNHA AR; MARTINS D. 2009. Classificação climática para os municípios de Botucatu e
São Manuel, SP. Irriga 14: 1-11.

FILGUEIRA FAR. 2008. Novo manual de olericultura: agrotecnologia moderna na produção e comercialização de hortaliças. Viçosa: UFV. 421p.

FONTES PCR. 2005. Olericultura: teoria e prática. Centro de Ciências Agrárias, Departamento de Fitotecnia. Viçosa: UFV. 486p.

GUIMARÃES VF; ECHER MM; MINAMI K. 2002. Métodos de produção de mudas, distribuição de matéria seca e produtividade de plantas de beterraba. Horticultura Brasileira 20: 505-509.

HORTA ACS; SANTOS HS; CONSTANTIN J; SCAPIM CA. 2004. Interferência de plantas daninhas na beterraba transplantada e semeada diretamente. Acta Scientiarum 26: 47-53.

MALUF WR. 2001. Heterose e emprego de híbridos $\mathrm{F}_{1}$ em hortaliças. In: NASS LL; VALOIS ACC; MELO IS; VALADARES MC. (eds). Recursos genéticos e melhoramento: plantas. Rondonópolis: Fundação MT. p. 327-356.

MINAMI K; CARDOSO AII; COSTA F; DUARTE FR. 1998. Efeito do espaçamento sobre a produção em rabanete. Bragantia 57: 169-173.

PURQUERIO LFV; DEMANT LAR; GOTO R; VILLAS BOAS RL. 2007. Efeito da adubação nitrogenada de cobertura e do espaçamento sobre a produção de rúcula. Horticultura
Brasileira 25: 464-470.

RAIJ B; ANDRADE JC; CANTARELLA H; QUAGGIO JA. 2001. Análise química para avaliação da fertilidade de solos tropicais. Campinas: Instituto Agronômico de Campinas. 285p.

TOLENTINO JÚNIOR CF; ZÁRATE NAH; VIEIRA MC. 2002. Produção da mandioquinha-salsa consorciada com alface e beterraba. Acta Scientiarum 24: 1447-1454.

TRANI PE; CANTARELLA H; TIVELLI SW. 2005. Produtividade de beterraba em função de doses de sulfato de amônio em cobertura. Horticultura Brasileira 23: 726-730.

TRANI PE; PASSOS FA; TAVARES M; AZEVEDO FILHO JA. 1997. Beterraba, cenoura, rabanete e salsa. In: RAIJ B; CANTARELLAH; QUAGGIO JA; FURLANI AMC. Recomendações de adubação e calagem para o estado de São Paulo. 2. ed. Campinas: Instituto Agronômico e Fundação IAC. p.174.

ZÁRATE NAH; SANGALLI CMS; VIEIRAMC; GRACIANO JD; MUNARIN EEO; PAULA MFS. 2010. Cobertura do solo com cama de frango, com e sem amontoa, na produção de beterraba. Ciência e Agrotecnologia 34: 1598-1603.

ZÁRATE NAH; VIEIRA MC; RECH J; GRACIANO JD; GOMES HE; PONTIM BCA. 2008. Número de fileiras no canteiro e espaçamento entre plantas na produção e na rentabilidade da beterraba em Dourados, estado do Mato Grosso do Sul. Acta Scientiarum 30: 397- 401. 